\title{
Los comienzos del morfing y del SMS en la publicidad televisiva española
}

\author{
Victoria TUR-VIÑES \\ Dra. Universidad de Alicante - España \\ Victoria.Tur@ua.es \\ Jesús SEGARRA-SAAVEDRA \\ DEA Universidad de Alicante - España \\ jesus.segarra@ua.es
}

\begin{abstract}
Resumen
Agencias y anunciantes siguen apostando por la televisión. Los lanzamientos de marcas y productos se realizan bajo fórmulas destacadas que estimulan la notoriedad, favorecen el recuerdo de los consumidores e incentivan la comunicación viral, convirtiendo así a los destinatarios de los mensajes en soportes y transmisores. Después de una etapa inicial de desconocimiento e inseguridad en formatos publicitarios no convencionales, asistimos al despegue en el uso de las iniciativas especiales de publicidad etiquetadas por la Ley 22/1999 como "otras fórmulas". La Ley General de la Comunicación Audiovisual 7/2010 sintetizó los formatos de comunicación comercial audiovisual en: mensaje publicitario televisivo o radiofónico, patrocinio, televenta y emplazamiento de producto. No obstante, la normativa no ha aportado demasiada luz sobre los formatos emergentes y futuros que ahora comprobamos cómo se han consolidado, mutado e hibridado. Este artículo centra su atención en dos formatos: los SMS (Short Message Service) en su transición hacia las redes sociales, y el morfing, entendido como las transiciones de la mosca (o imagotipo) de la cadena en el logotipo de la marca del anunciante. Es algo más que un patrocinio televisivo o una primera posición de bloque, ya que capta la atención del espectador por su impacto, novedad y creatividad. Estos formatos circulan por las cadenas televisivas, pero también entre los vacíos legales y la delgada línea que divide la programación estrictamente televisiva de la publicidad.
\end{abstract}

Palabras Clave: Comunicación comercial; morphing; publicidad no convencional; redes sociales; SMS; televisión; Twitter

\section{The beginnings of morphing and SMS in Spanish television advertising}

\begin{abstract}
Agencies and advertisers are using television in their media plans. The brand and product launches use ways with prominent presences that improve visibility, promote the consumers memory and stimulate viral communication, changing thus the media recipients into supports and transmitters. After an initial stage of ignorance and insecurity as far as non conventional advertising formats are concerned, we live the launch in the use of special initiatives in television advertising by advertisers, especially, that Law 22/1999 labeled as "other forms". The General Law on Audiovisual Communication 7/2010 synthesized audiovisual commercial communication formats as: television or radio advertising message, sponsorship, teleshopping and product placement. However, the legislation didnt provide much light on the emerging and future formats that now we see how they have consolidated, mutated and hybridized. This papper focuses on two forms: the different uses of SMS (Short Message Service) in their transition to social networks, and morphing, understood as the transitions of the logotype (or logo) into the advertiser's brand. It is more than a television sponsorship or first position in a block, because it captures the viewer's attention for its impact, novelty and creativity. These formats circulate on the television channel, but also between the legal vacuum and the thin line between strictly television programming and advertising.
\end{abstract}


Key Words : Business comunication; morphing; non conventional advertising; social networks; SMS; television; Twitter

\section{Referencia normalizada:}

Tur Viñes, V.; Segarra Saavedra, J. (2013) Los comienzos del morfing y del SMS en la publicidad televisiva española. Historia y Comunicación Social. Vol. 18 No Especial Octubre. Págs. 555-570.

Sumario: 1. Introducción. 2. Morphing, un híbrido publicitario entre la cadena y el anunciante. 3. SMS: un nuevo y efímero negocio televisivo/publicitario. 4. SMS: el efímero negocio televisivo. 5. Conclusiones. 6. Referencias.

\section{Introducción}

En 1990 el panorama televisivo español evolucionó hacia lo que hoy se entiende como un mercado de libre competencia sui géneris. Las televisiones públicas tienen una doble vía de financiación y las privadas se sustentan exclusivamente con la publicidad y los derechos derivados de los contenidos o del licensing.

Hasta la década de los 90, el formato más habitual era el spot convencional. Las iniciativas especiales eran anecdóticas. Se limitaban a programas de producción propia del corte de Un, dos, tres... responda otra vez (TVE 1, 1972-2004). Una de las marcas pioneras en optar por esta fórmula fue Batidos Okey (Nutrexpa) patrocinando un concurso dentro de Un, dos, tres... donde unos ficticios del producto permitían concursar, comunicar los sabores de los productos y entregar premios. En el mundo anglosajón ya era una práctica frecuente (Pla y Moreno, 1998; Szybowicz y Magistrali, 2000; Rossiter y Percy, 2003). Con la llegada de Telecinco, este tipo novedoso de publicidad alcanzó su mayor versatilidad, llegando a suponer el $20 \%{ }^{1}$ del volumen de inversión en la cadena.

Por el grado de integración publicidad/programa podemos entender un formato publicitario no convencional como cualquier acción que integra la comunicación de un producto/marca en un espacio televisivo. Por exclusión, podemos decir que se trata de toda acción que no entra en las habituales campañas convencionales de spots en el break comercial.

Existen muchos formatos considerados no convencionales: el bartering (contenidos producidos por anunciantes y cedidos o vendidos a las televisiones), el sponsoring (patrocinio televisado habitual en eventos deportivos), la telepromoción (espacio comercial que utiliza algún elemento de un programa -actores, escenarios, jerga, música...- para comunicar), el patrocinio (la marca aparece en lugares preferentes

1 Datos internos de 1992. Depto. de Marketing de Publiespaña (concesionaria de Telecinco), empresa donde la autora desarrolló su actividad profesional entre 1990-1994, dentro del Departamento de Iniciativas Especiales. 
ofreciendo el programa), el product placement (la presencia ostensible del producto en guión o localizaciones pertinentes, integrados con la trama del contenido), aunque, en esta última fórmula haya autores que defiendan que entra en el dominio de las relaciones públicas y no de la publicidad (Baker \& Crawford, 1995; Victoria, 1999; Méndiz, 2000).

En 2007, asistimos al surgimiento de nuevas fórmulas como el morphing (presencias de marca en los momentos de transición de los programas a la publicidad o viceversa, integrados con el imagotipo de la cadena) o los mensajes SMS de opinión o compra de contenidos, donde las marcas comercializadas reinventaron al anunciante. Mientras que el morphing perdura en la actualidad y ha adoptado sofisticadas fórmulas, los SMS pronto dejaron paso a las redes sociales. Tres fueron los motivos fundamentales: la gratuidad, la inmediatez y la posibilidad de conversación.

En Europa, los orígenes de este tipo de publicidad se ubican en Italia. La primera iniciativa tuvo a la marca Dixan como protagonista. Fue en 1981 en el programa Tombolissima. La marca consiguió que 40 emisoras privadas emitieran en cadena, todo un hito histórico promovido por el interés comercial de un anunciante (Grasso, 1992).

El valor de este tipo de presencias no convencionales es difícil de calibrar pero uno de los primeros informes económicos que las reflejaba les otorgaba entre el 15 y el $20 \%$ de la inversión publicitaria en televisión de la época (Infoadex, 2004).

En España, el período de surgimiento (1990-95) estuvo marcado por la experimentación de todo tipo de fórmulas novedosas. Telecinco fue pionera en el desarrollo de estas iniciativas, seguida por Antena 3, reportando enormes beneficios para el anunciante. Cuando el formato implicaba concurso y participación, el volumen de respuesta era masivo aunque hay que reconocer que la elección del tipo de programa, el grado de implicación del conductor del mismo, el acierto de los guiones y las mecánicas de interacción, intervenían claramente en el éxito de las iniciativas. Merecen especial mención las telepromociones del VIP, Very Important People (Telecinco, 1990-1992), conducidas por Emilio Aragón y Belén Rueda y protagonizadas por marcas como Pascual, Fontvella, Gallina Blanca o Trex.

Todas estas presencias están sujetas a un marco jurídico mutante en la última década del pasado siglo, que explicaría su variable práctica a lo largo del tiempo. Algunas de ellas han sido asimiladas en una sola categoría y han sido consideradas legalmente como patrocinios (Corredoira y Alfonso, 1991). Cada vez que surgía una ley se aprecia un período de abstinencia en el uso de este tipo de fórmulas, porque el mercado publicitario necesita estudiar con detenimiento lo que, a partir de la ley, 
era legal o no hacer en televisión. Así, entre 1994 (LTV 94²) y 1999 (LTV99³) encontramos un periodo de incertidumbre donde fue casi imposible encontrar este tipo de formatos en las pantallas.

Tras el desarrollo regulador motivado por la convergencia con Europa, a partir del 2000 resurgieron este tipo de fórmulas. Es esperable que la innovación en las formas de estar en televisión fluya desde este tipo de formatos ya que el spot convencional está denostado y frecuentemente cuestionado como fórmula eficaz.

Su eficacia ha sido comprobada (Stout y Burda, 1989; Reinares y Reinares, 2003). Babin y Calder (1996) demostraron que las marcas que recurrían al product placement eran más memorables. Tanto su rentabilidad (Sleight, 1992; Girone y Zigoni, 1993; Corredor, 1997; Pérez 1999a y 1999b) como su polimorfismo -la versatilidad de integración en los programas-(Del Pino, 2006) o la percepción atractiva por parte de los espectadores (Nebenzahl y Secunda, 1993; Karrh, 1995) han sido contrastadas por la investigación.

Las ventajas de este tipo de formatos no convencionales se podrían concretar en:

- La imagen cobra importancia frente a modos de comunicación tradicionales.

- La actitud crítica del consumidor aleccionado obliga a incrementar el valor de ocio/interacción de la publicidad.

- Se ven, recuerdan y gustan más.

- Distinguen frente a la competencia.

- Establecen sinergias y transferencias de valores entre la imagen programa/ presentador y el producto o servicio.

- Representan una comunicación más completa porque:

1. Según formato, disponen de más tiempo.

2. Comunican de forma más natural, si están bien diseñadas e interpretadas.

3. Son más espontáneas, si se graban en directo o en tiempo real, con poca postproducción.

4. Generan mensajes interrelacionados con los contenidos programáticos.

5. Se facilita la relación recuerdo-identificación-motivación de compra.

- La cadena de televisión presta un mejor servicio al anunciante en la resolución de sus necesidades de comunicación comercial.

2 Ley 25/1994, de 12 de julio por la que se incorpora al Ordenamiento Jurídico Español la Directiva 89/552/CEE, sobre la coordinación de disposiciones legales, reglamentarias y administrativas de los Estados miembros, relativas al ejercicio de actividades de radiodifusión televisiva (LTV94).

3 Ley 22/1999, de 7 de junio, de Modificación de la Ley 25/1994, e incorpora al ordenamiento jurídico español la Directiva 97/36/CE, de 30 de junio, del Parlamento Europeo y del Consejo que modifica la Directiva anterior (89/552/CEE) con motivo del Acta de adhesión de 1994 (LTV99). 
- Dependen de la capacidad creativa y comercial de la cadena para proponer espacios ad hoc para el anunciante.

La suma de todos estos elementos explicaría por qué una cadena recibe por publicidad más de lo que le correspondería por la cuota de pantalla (share) que ostenta. Sólo a través de las iniciativas especiales la cadena de televisión consigue un servicio comercial diferenciado, su gran activo.

El anunciante evita la saturación que provoca la publicidad convencional y, la agencia o central de medios introduce elementos novedosos en la gestión del presupuesto y aumenta su competencia a través de estrategias de diferenciación. En contra, los formatos especiales suponen mayor esfuerzo económico y mayor complejidad en la producción.

\section{Morphing, un híbrido publicitario entre la cadena y el anunciante}

El espectador está acostumbrado a los avisos de transición a publicidad. Sabe que a partir de ese momento diferentes marcas, de forma sucesiva, tratarán de impresionarle y estimular su recuerdo. Pero lo que no espera es encontrar publicidad en ese mismo aviso, en el momento de máxima proximidad con el contenido programático que ha decidido ver, cuando las caretas corporativas de la cadena se transforman y, en un breve juego visual, cobra movimiento fugaz, a modo de cortinilla de publicidad, transición por requerimiento legal.

Por esta razón, desde 2007, algunos lanzamientos recurren a un nuevo formato: el morphing. Se trata de comunicaciones publicitarias previas o posteriores a los bloques publicitarios de cada programa y cuya función es la del recuerdo del paso a publicidad o del retorno al programa con una duración de 3 a 7".

Se trata del máximo grado de fusión con la imagen de la cadena. Nos parece especialmente oportuno cuando la marca de la cadena ya está consolidada y siempre que sea una acción puntual, como el lanzamiento de un nuevo producto, y no se perpetúe en el tiempo. De lo contrario, perdería impacto y, con ello, eficacia. Se trata de un formato que no contempla la actual Ley 7/2010 (igual que otros formatos especiales). Además, este tipo de publicidad permite que la marca no se identifique sólo con un programa, sino con la globalidad de la cadena de televisión.

Entre los primeros morphing detectados encontramos el lanzamiento de la nata Central Lechera Asturiana ${ }^{4}$ (Imagen 1) en 2006. Más tarde, numerosas marcas han escogido esta fórmula, necesariamente acotada en el tiempo, por coste económico y por exceso de notoriedad.

4 Cfr. en http://goo.gl/clRTBF 
Imagen 1: Frames del morphing de Central Lechera Asturiana. Fuente: TVE 1

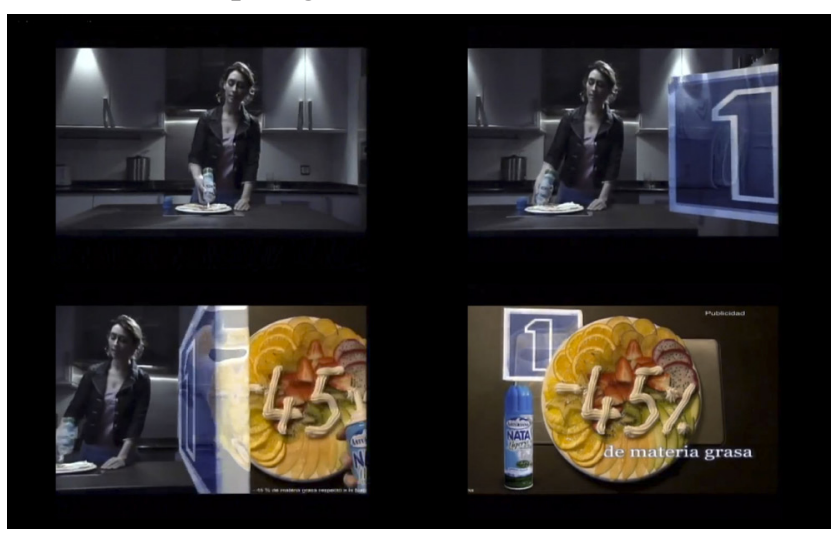

En el morphing de TVE 1, el grado de unión marca comercial e imagen de la cadena no es muy elevado. Aparecen juntas, en un espacio exclusivo, pero podríamos considerarlo un morphing "en adición" más que un morphing auténticamente "simbiótico". La marca utilizó varias cadenas en paralelo para el lanzamiento de la nata. En Telecinco, encontramos otra creatividad, mucho más transgresora que implica un mayor grado de simbiosis (Imagen 2), pues el producto dibuja en un gesto lúdico y divertido que transmite a la perfección la percepción habitual sobre el producto.

Imagen 2: Frames del morphing de nata Central Lechera Asturiana. Fuente: Telecinco

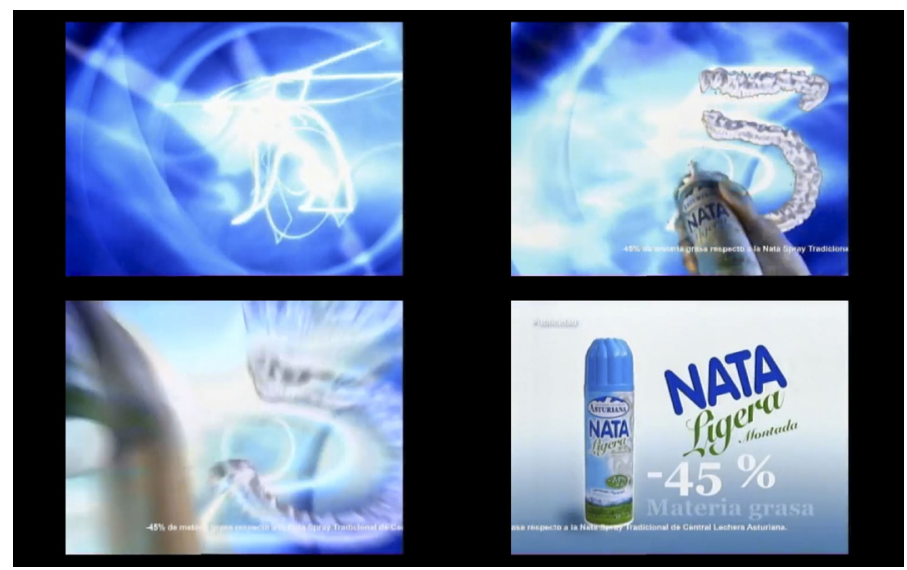

La misma marca, en el mismo período de tiempo pero en otra cadena-Telecincoy con distinto producto -la leche- presentó otra creatividad más próxima al formato "morphing simbiótico" (Imagen 3). 
Imagen 3: Frames del morphing de leche Central Lechera Asturiana. Fuente: Tele 5

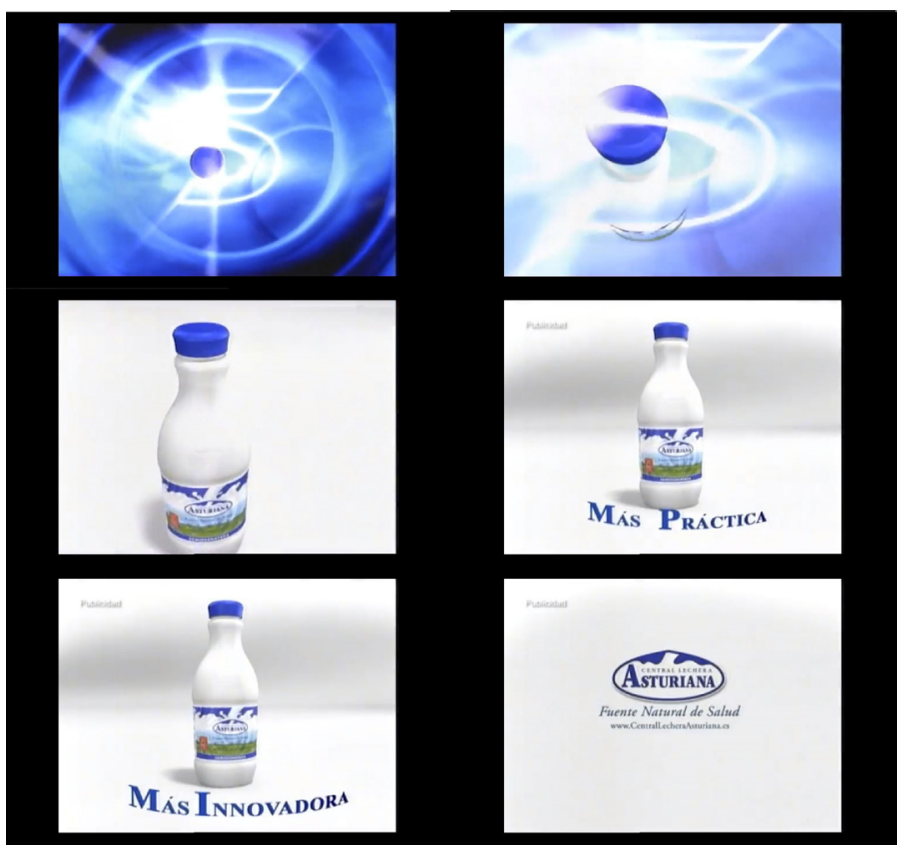

Percibimos diferencias ostensibles entre la creatividad de la cadena pública y Telecinco, en el estilo y grado de integración marca-imagen cadena.

El lanzamiento de JB Twist ${ }^{5}$ (Imagen 4) y el de Vodafone (Imagen 5) también se apoyaron en este formato, como complemento de una campaña en medios de gran envergadura.

Imagen 4: Frames del anuncio de JB Twist. Fuente: Telecinco

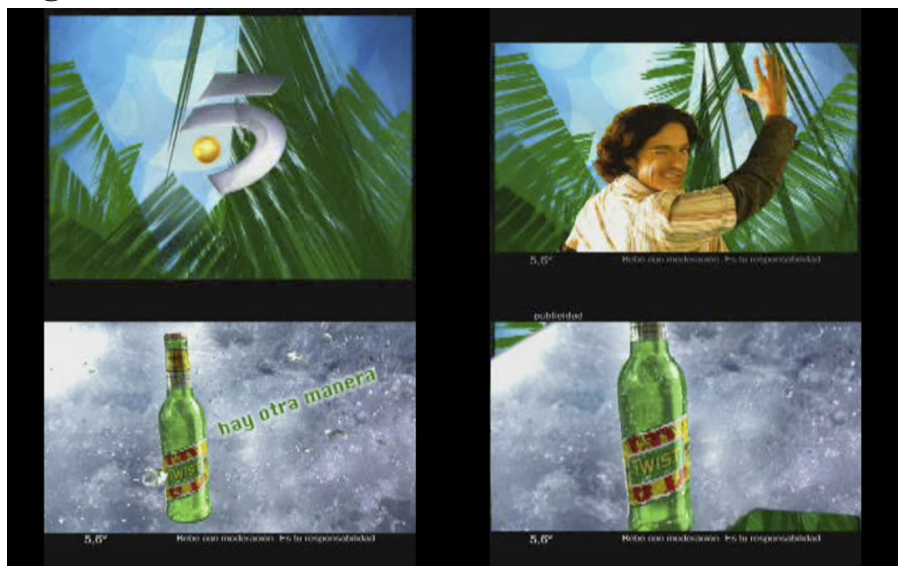

5 Cfr. en http://goo.gl/7Ncm $4 \mathrm{~d}$ 


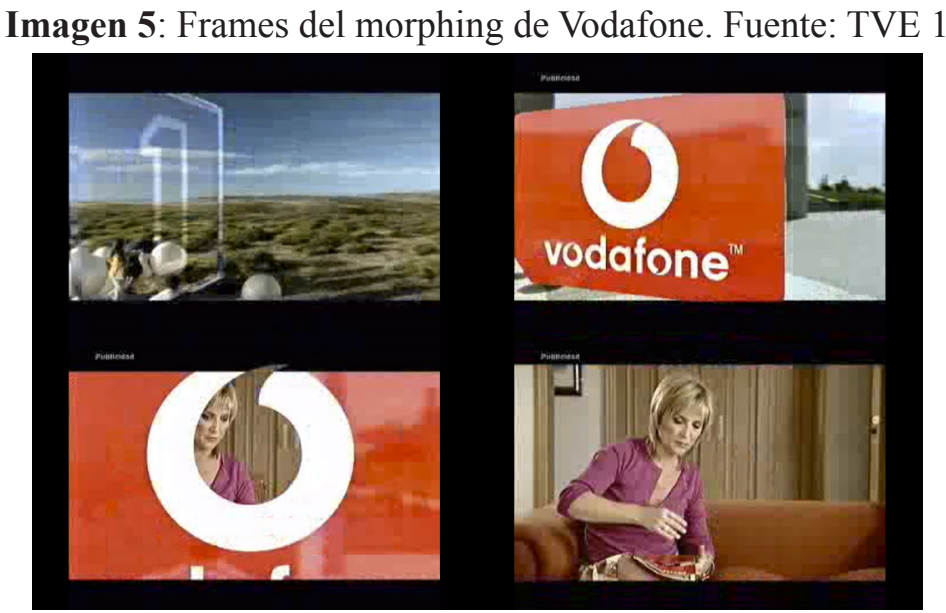

Este tipo de formato admite multitud de creatividades. Tendremos que estar atentos a la evolución de este nuevo formato publicitario televisivo.

\section{Sms: el efímero negocio televisivo}

En la primera década del siglo XXI surge un nuevo negocio que se sale de la tradicional relación anunciante-medio, para fusionar ambos conceptos de forma casi inseparable, dando lugar a una nueva fuente de ingresos para las cadenas.

Nos referimos a los mensajes SMS que inundaban los quintos inferiores de las pantallas de las televisiones. Su surgimiento estuvo acompañado de polémica.

El software fue ideado por un alicantino, Joaquín Ibáñez, quien obtuvo la patente en mayo de 2002. El sistema resolvía muchos problemas técnicos y permitía a las televisiones emitir un juego o concurso e invitar a los telespectadores a participar en el mismo mediante el envío de SMS.

Los mensajes se evaluaban conforme a los siguientes parámetros: normas de participación, formato de los mensajes, claves de códigos o validación de las respuestas y los premios o recompensas a asignar. La idea permitía dar protagonismo a los telespectadores en la toma de decisión del desarrollo de un concurso, por ejemplo, seleccionando un participante del programa-reality o echándolo.

Se posibilitaba una verdadera interacción a tiempo real que ni siquiera necesita de la grabación en directo. Lejos quedan aquellos primeros intentos por interactuar a través de la compra de dispositivos especiales como hizo Telecinco con el programa El juego de Hugo, destinado al público infantil, a principios de los 90.

Animatic Informática, la empresa de Joaquín Ibáñez, contactó con Antena 3 para el uso de este sistema y firmó con la cadena un contrato en 2000 por dos años. 
La primera vez que se emitió un concurso basado en SMS fue en la serie Los Simpsons (Antena 3, 1991-) en marzo de 2001, antes de que Animatic obtuviese la patente. El 26 de marzo de 2001 se vio el primer contenido ("¿Sabes cuántos pelos tiene Hommer Simpson? Envía 0,1 ó 2 al 343"). No se daba ningún tipo de premio y contestaron 40.000 personas. Después, los espectadores empezaron a enviar mensajes al 343, preguntando cosas como por qué habían quitado Compañeros (Antena 3, 1998-2002) de la parrilla. La cadena detectó una necesidad a cubrir: la interactividad. Animatic también tuvo contactos con TVE 1 para incluir el sistema de SMS en varios concursos. Sin embargo, la cadena pública optó por la empresa Movilisto.

Gráfico 1: Intención de inversión. Fuente: McKinsey

Would you allocate more ad spending to a channel offering attractive ratings growth-for example, via new technologies such as SMS?

$\%$ of respondents $(n=124)$

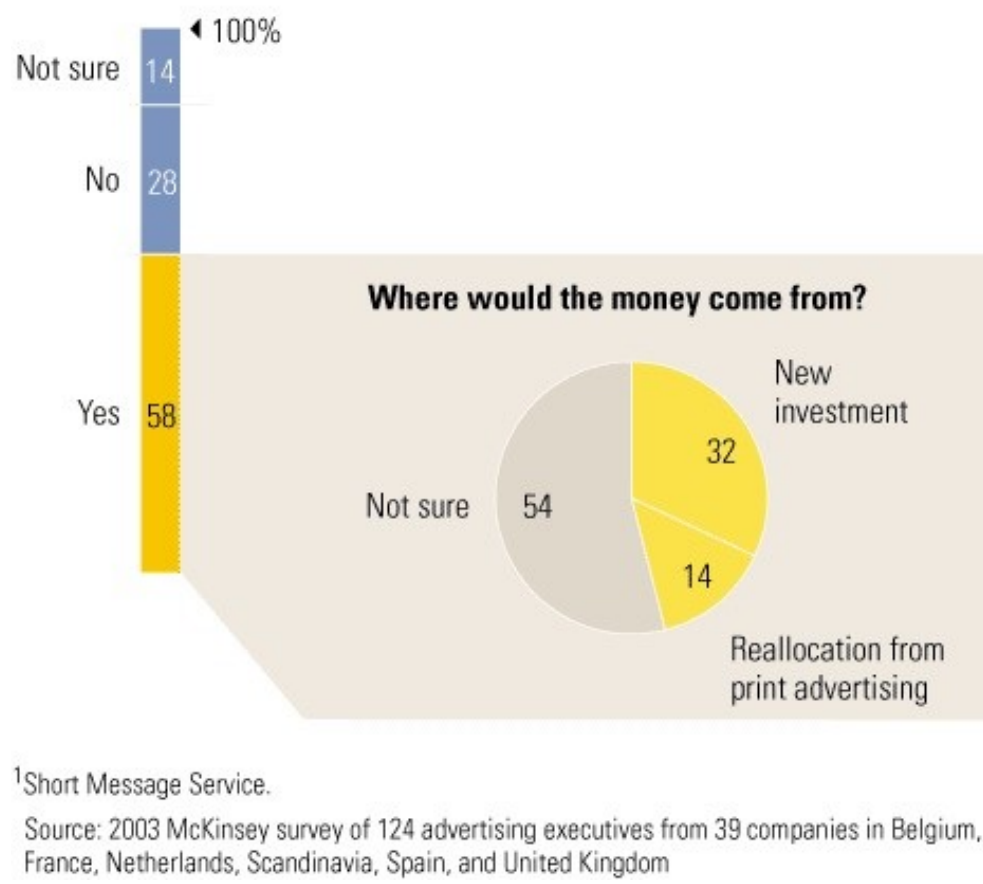

A pesar de que Antena 3 tenía un contrato por dos años, una vez finalizado, siguió utilizando el sistema, por lo que Animatic Informática presentó una demanda en 2003, por el uso en concursos como Operación Triunfo (TVE 1, 2001-2004; Telecinco 20052011) y Pasapalabra (Antena 3, 2000-2007; Telecinco 2007-). La demanda también involucraba a las productoras Gestmusic Endemol S.A., Boca a Boca Producciones S.L., y la compañía Movilisto S.A. Según la demanda, estas televisiones y empresas realizaron una acción de violación de patente, de propiedad intelectual, incumpli- 
miento contractual, por lo que solicitó una indemnización por daños y perjuicios. En 2006 se desestimó dicha demanda al no diferenciar las reivindicaciones de la propiedad intelectual de las ventajas comerciales obtenidas.

El estudio de McKinsey sugiere que los televidentes que usan sus teléfonos móviles para enviar mensajes de texto a programas de televisión son más propensos a sintonizar ese programa otra vez, a hablar a sus amigos sobre los programas, y a comprar productos asociados. Este interés añadido puede incrementar los ratios hasta un $20 \%$ para programas generalistas, y hasta un $100 \%$ en el caso de programas dirigidos a un segmento específico.

El estudio preguntó a 124 ejecutivos de publicidad de 39 empresas de Europa occidental, si estarían dispuestos a gastar más dinero en canales que ofrezcan este tipo de programas. Más de la mitad afirmaron que sí estarían dispuestos, y un tercio realizarían una inversión adicional.

Los mensajes SMS Premium eran mensajes que ofrecían una retribución. Por ejemplo, en un concurso con el nombre PLATOS, las personas que querían participar podían enviar un mensaje SMS del tipo MENS PLATOS a un número corto de cuatro dígitos.

Este nuevo y efímero negocio dio lugar a un departamento nuevo en Antena 3 televisión: Contexta. El volumen de negocio supuso 31 millones de euros anuales para la cadena. Contexta gestionaba diferentes productos, algunos de ellos siguen siendo objeto de negocio bajo distintas fórmulas: descargas para móviles, melodías, mensajes personalizados, fotografías y logos...

Estas fórmulas facilitan, además, la medición de impactos.

La introducción del móvil en nuestras vidas, tuvo entre 2006 y 2007 el máximo apogeo. El 98\% de la población adquirió en esa época el dispositivo. Aprovechando la circunstancia, Contexta comercializó ocho pases diarios de cada producto.

En este nuevo negocio, la cadena consiguió comercializarse a sí misma, a través de productos licenciados que publicitaba en su espacio libre, como televenta, ocupando los 5 minutos máximos por hora que legalmente están estipulados por ley.

A este respecto, la Ley $7 / 2010^{6}$, en el artículo 13 recoge el derecho de las televisiones a crear canales de comunicación comercial y programas o anuncios de autopromoción, es decir, publicidad de su programación, anuncios de sus propios programas o de los productos accesorios derivados directamente de dichos programas (libros de recetas, discos, versiones originales, DVDs con series...). Así, indica que:

"Estos programas y anuncios no se considerarán comunicación comercial a los efectos de esta Ley. No obstante, para la comunicación audiovisual televisiva, el

6 Ley 7/2010, de 31 de marzo, General de la Comunicación Audiovisual, de conformidad sobre la constitución del registro Estatal de Prestadores de Servicios Audiovisuales y de conformidad sobre comunicación comercial televisiva (Real Decreto 1624/2011). 
tiempo dedicado a los anuncios publicitarios sobre sus propios programas y productos no podrá superar los 5 minutos por hora de reloj" (Ley 7/2010, Art. 2, punto 2).

El precio de la llamada no era arbitrario. La Comisión del Mercado de las Telecomunicaciones (CMT) del Ministerio de Economía marcó las tarifas: 0’30, 0’60, 0’90 ó 1'2 euros. Existían diferentes tipologías:

- $\quad(343,7343,5558)$ se enviaba un mensaje y se recibía algo a cambio.

- (7755) se enviaba un mensaje y quedabas suscrito a un servicio de información (por ejemplo Alerta Aries que te mandaba todos los días el horóscopo).

Los ingresos generados por llamadas quedaron repartidos entre los operadores, la plataforma y Antena 3. Entre las acciones de la cadena vinculadas a los SMS recordamos:

- Antena 3 produce la versión de Torrente. A cambio, la cadena fue la primera en emitirla, explotarla en DVD, potenciarla vía SMS...

- Otra acción de éxito fue el anteriormente comentado "Neng", un producto exclusivo de Antena 3.

\section{La transición del sms a las redes sociales}

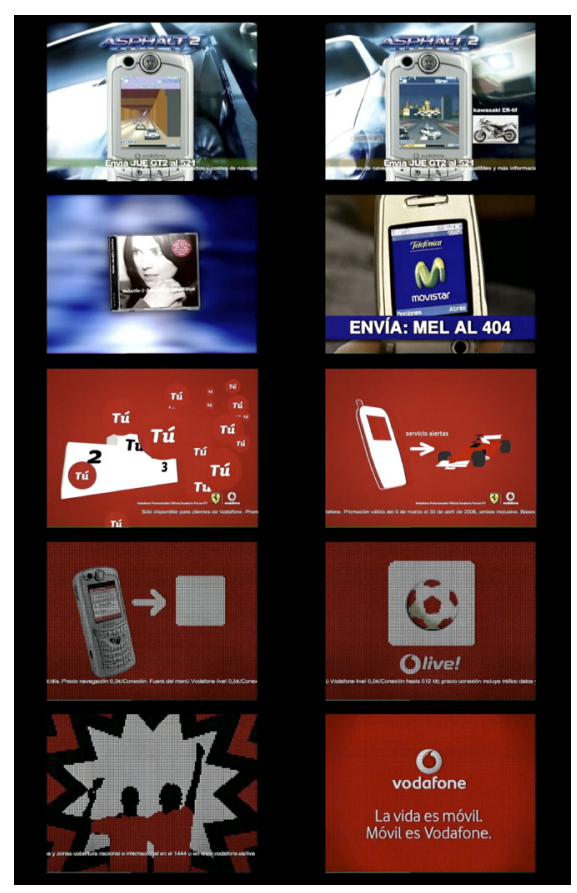

Diferente ha sido el uso de la televisión como medio de difusión de mensajes comerciales que persuadían al espectador para el envío de SMS (short message service) y MMS (multimedia messaging system). Por una parte, los que emitían las operadoras de telefonía para incitar a la descarga de juegos, melodías, alertas y suscripciones. Por otra, los que difundían las cadenas en sorteos, llamadas a la participación y la interactividad.

Los primeros incluían textos prácticamente ilegibles. La letra pequeña de los spots nos daba a conocer las condiciones para el envío de SMS y MMS a los operadores de telefonía, bases de concursos, tarifas... Además, las franjas inferiores donde se situaban estos dificultaban en ocasiones su lectura por la falta de contraste y la rapidez con la que pasaba el texto.

Imagen 6. Frames de los spots para la descarga de juegos, melodías para el móvil, descarga y suscripción a alertas vía SMS. Fuente: Infoadex 
Estos spots se emitían en el break publicitario. En cambio, las televisiones invitaban al envío de SMS en sus programas.

Imagen 7. Frame del microconcurso de TVE con líneas 905 y envío de SMS. Fuente: www.tencuidado.es

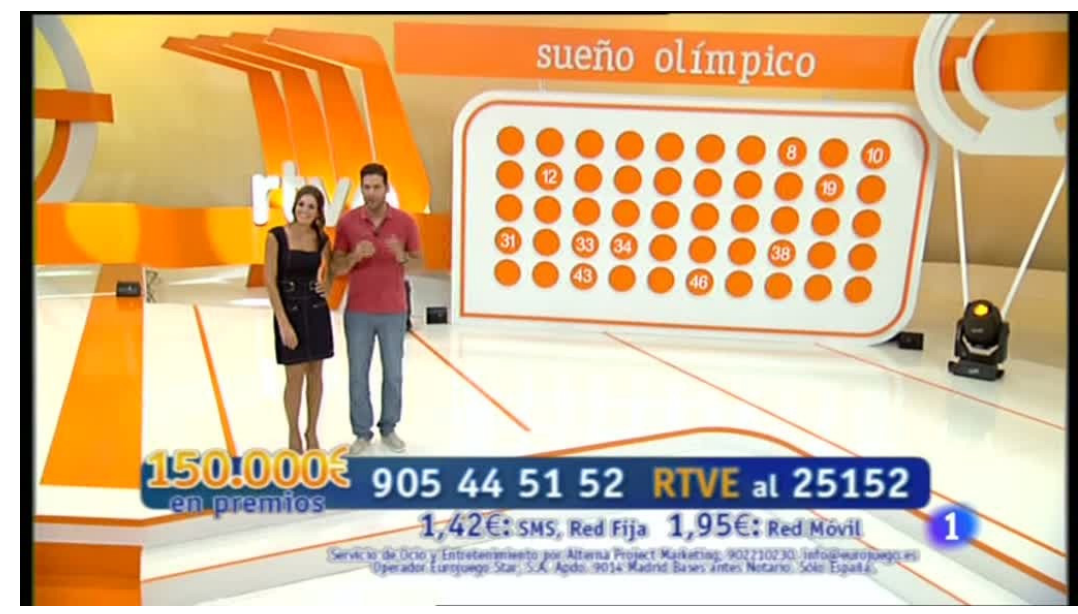

También buscaban la interacción de los espectadores mediante el fenómeno conocido como chat TV, propio de magazines que trataban temas de actualidad y sociedad. Incrementaban así las posibilidades de simultaneidad narrativa, propias de la retransmisión en directo. Eran una fuente de financiación para las televisiones. Mediante palabras clave propuestas desde el programa, los espectadores podían enviar sus opiniones y sugerencias al programa.

Los anunciantes también han hecho uso del envío de SMS con intencionalidad publicitaria. Esta técnica permitía llegar a la mano del consumidor de forma directa y personalizada. No obstante, esa inmediatez provocaba cierta intrusión en el consumidor y generaba su rechazo.

La manera en la que vemos televisión ha cambiado desde la llegada de las tecnologías portátiles. También ha variado la forma de interactuar con la televisión con la aparición de las redes sociales. Tanto que si hace años con la aparición de las cadenas temáticas y digitales asistíamos a la fragmentación de las audiencias, ahora, con la televisión social la fragmentación vuelve a producirse de la mano de Twitter, Facebook... Porque en la actualidad vemos nuestros programas favoritos por televisión en directo, desde su web también en diferido o vía streaming, los seguimos por las redes sociales o incluso combinamos la recepción televisiva con la participación en los social media. Se suman otras herramientas de interactuación las aplicaciones móviles como Whatsapp, Line, llegando a hacer de los contenidos objeto de la viralidad. Y de los destinatarios y sus círculos de influencia, canales de transmisión.

Internet supuso un cambio. Pero la revolución más significativa fue la aparición de la Web 2.0 o web social (O'Reilly, 2005). La multipantalla es un fenómeno tecnoló- 
gico que reúne tabletas, teléfonos, ordenadores o televisores inteligentes delante del espectador. Interaccionan entre sí con la cadena y con el espectador. Su uso depende del usuario y de la hora de su consumo.

Gráfico 2. Pantallas o dispositivos con acceso a Internet Fuente: La Sociedad de la Información en España 2012

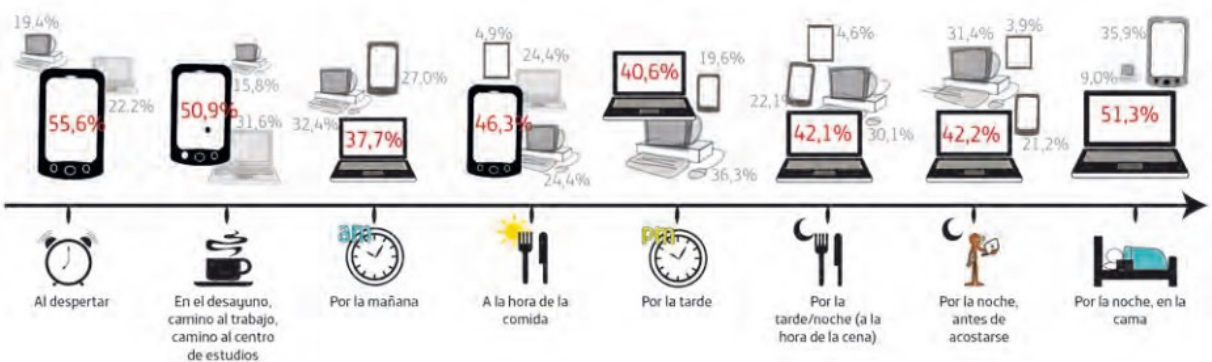

Con las redes sociales, la audiencia del programa no se reduce, sino que el seguimiento de este mejora con ellas. Además, las conversaciones en las redes sociales aumentan el consumo de televisión en directo. Tanto es así que las redes sociales son consideradas como un aliado más en la estrategia comercial.

Con la Televisión 2.0 las experiencias multipantalla se hacen realidad. El resultado es la denominada enhanced TV o televisión mejorada. Sus virtudes son la interactividad, bidireccionalidad, inmediatez, rapidez, fluidez y frescura; la capacidad de personalizar contenidos alternativos y diferenciales para el espectador; seducir a nuevos espectadores y fidelizar a los actuales. Es decir, mejorar los rating de audiencia para incrementar los ingresos publicitarios.

De todas las redes sociales, Twitter es la herramienta que mayor interactividad e interacción proporciona a los espectadores de televisión. Ahora las etiquetas que guían las conversaciones en las redes sociales son los hashtags.

Imagen 8. Frame del programa La Sexta noche con el hashtag. Fuente: http://www. lasexta.com/

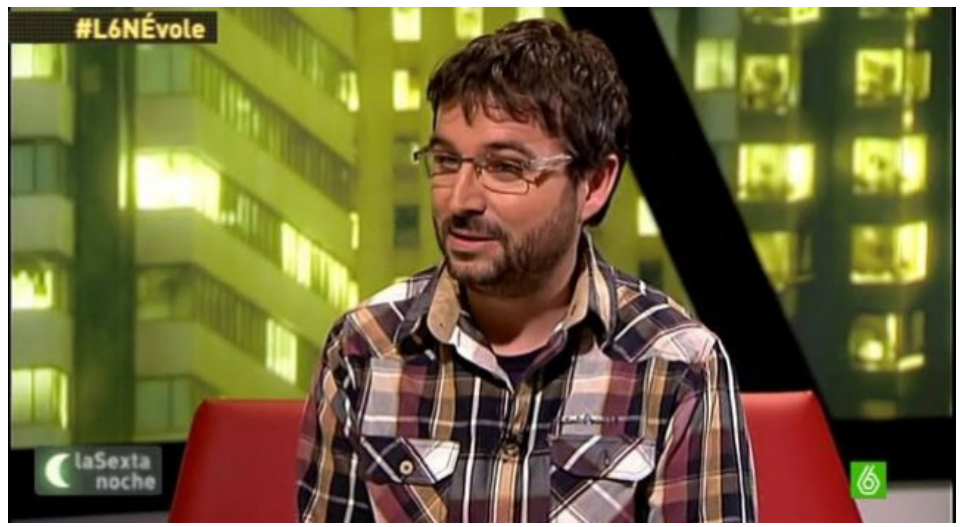


Las redes sociales son un motor de influencia social, no sólo en el mercado televisivo. También en el publicitario. Ambos están directamente relacionados. Recordemos si no la retirada del programa La Noria (Telecinco, 2007-2012) tras la críticas de los espectadores y la consiguiente retirada de sus anunciantes.

Dentro de esta nueva situación, compleja a la par que estimulante, el mercado publicitario tiene un nuevo reto. Su nombre es Social TV Analytics, "que se encarga de medir y analizar las conversaciones en medios sociales sobre programas de televisión para poder proporcionar información a cadenas de televisión, productoras de contenidos y anunciantes" (Gallego, 2013: 28).

\section{Conclusiones}

Las motivaciones de estas acciones no siempre tenían los mismos orígenes ni los mismos fines. Es de resaltar el caso de una acción social vía SMS que tuvo una respuesta masiva con motivo de solicitar ayuda para los afectados por el Tsunami, en enero de 2005. Antena 3 hizo una campaña memorable. En todos los programas de producción propia, si enviabas la palabra AYUDA, tu dinero iba destinado a ayudar a los damnificados. Antena 3 y los operadores de telefonía renunciaron a su parte de beneficio ( 1 '2 euros por mensaje). Hacienda les confirmó que esta acción estaba exenta de IVA. Se consiguió recaudar 8.000 .000 euros, la mayor recaudación obtenida en España por una acción SMS hasta el momento.

Sería deseable que los esfuerzos por innovar en los formatos publicitarios tuvieran con más frecuencia este tipo de fines sociales.

Resulta curioso comprobar que son las televisiones privadas las que más arriesgan en la búsqueda de nuevos formatos o negocios. Detrás de los dos formatos que hemos comentado en estas líneas, siempre encontramos una cadena o plataforma privada. La experimentación, en el campo de la televisión, es impulsada desde el ámbito privado.

El mundo de la televisión está en permanente evolución. Sin duda, será apasionante asistir al surgimiento de nuevas formas de presencia que mejoren la comunicación de las marcas con sus públicos. Seguiremos atentos.

Agradecemos la colaboración del letrado Gonzalo Sánchez Imbernón en los aspectos legales. 


\section{Referencias}

BABIN, L. A. \& CARDER, S. T. (1996). “'Viewers' recognition of brands placed within in a film". En: International Journal of Advertising, $\mathrm{n}^{\circ}$ 15, Oxfordshire: Marston Book. p. 140-151.

BAKER, M. \& HAZEL, C. (1995). "Product Placement". En: Working Series, no 95/2, Glasgow: Ed. University of Strathclyde, Dept. of Marketing.

CORREDOIRA Y ALFONSO, L. (1991). Mecenas de pantalla: El patrocinio de programas de televisión. Ed. Del Drac: Barcelona.

CORREDOR, P. (1997). "Product Placement, ¿un atrezzo rentable?". En Marketing $y$ Ventas, $\mathrm{n}^{\circ}$ 111, Madrid: Wolters Kluwer, p. 53-58.

DEL PINO ROMERO, C. et al. (2006). Brand Placement: integración de marcas en la ficción audiovisual. Evolución, casos, estrategias y tendencias. Barcelona: Gedisa.

FUNDACIÓN TELEFÓNICA (2013). La Sociedad de la Información en España 2012. Disponible en http://e-libros.fundacion.telefonica.com/sie12/aplicacion sie/ParteA/pdf/SIE_2012.pdf [03/09/2013].

GALLEGO, F. (2013). Social TV Analytics: Nuevas métricas para una nueva forma de ver televisión. En Index.comunicación: Revista científica en el ámbito de la Comunicación Aplicada, $\mathrm{n}^{\mathrm{o}}$ 3, Madrid, URJC. P. 13-39. Disponible en http:// journals.sfu.ca/indexcomunicacion/index.php/indexcomunicacion/article/ view/49/56. [04/09/2013].

GIRONE, P. y ZIGONI, B. (1993). La lógica de la emoción y del esponsor. Madrid: Díaz de Santos.

GRASSO, A. (1992). Storia della televisione italiana. Milano: Garzanti.

INFOADEX (2004). Informe anual sobre inversión publicitaria. Disponible en http:// www.infoadex.es/ [03/09/2013].

KARRH, James A. (1995). "Brand Placements in Feature Films: The Practitioners' view". En Proceedings of the 1995 Conference of the American Academy of Advertising. University of Florida, USA: MADEN, C. S. p. 182-188.

MÉNDIZ NOGUERO, A. (2000). Nuevas formas publicitarias: patrocinio, product placement y publicidad en Internet. Málaga: Universidad de Málaga-Manuales.

NEBENZAHL, I. \& SECUNDA, E. (1993). "Consumers' attitudes toward product placement in movies". En International Journal of Advertising, ${ }^{\circ} 12$, vol. 1, Oxfordshire: Marston Book. p. 1-11.

O'REILLY, T. (2005). What is Web 2.0: design patterns and business models for the next generation of software. Disponible en http://www.oreillynet.com/lpt/a/6228. [02/09/2013].

PÉREZ ZAFÓN, L. (1999a). "El 'placement' anda revuelto". En IP Mark, no 516, Madrid: Ediciones y estudios, p.18-19.

PÉREZ ZAFÓN, L. (1999b). "La controvertida efectividad del emplazamiento de producto". En IP Mark, no 520, Madrid: Ediciones y estudios, p. 40-41.

PLA, E. y MORENO, A. (1998). "Emplazamiento de productos a la española". En Campaña, no 522, p. 18-19. 
REINARES LARA, P. J. y REINARES LARA, E. M. (2003). Fundamentos básicos de la gestión publicitaria en televisión. Madrid: ESIC.

ROSSITER, J. R. \& PERCY, L. (1997). Advertising Communications and Promotion Management. EE.UU: McGraw-Hill.

SLEIGHT, S. (1992). Patrocinadores. Un nuevo y eficaz sistema de marketing. Barcelona: McGraw-Hill.

STOUT, P. A. \& BURDA, B. L. (1989). "Zipped Commercials: Are they Effective?" En Journal of Advertising, $\mathrm{n}^{\circ}$ 4, vol. 18, USA: American Academy of Advertising, p. 23-32.

SZYBOWICZ, A. y MAGISTRALI, S. (2000). Esponsorización y Mecenazgo. Barcelona: Gestión 2000.

VICTORIA MÁS, J. S. (1999). Hollywood y las marcas (Product Placement). Madrid: New Book Ediciones.

\section{Los autores}

Victoria Tur-Viñes. Profesora Titular del Departamento de Comunicación y Psicología Social de la Universidad de Alicante. España. Ex Senior Advertising Producer en Publiespaña (Grupo Fininvest). Sus líneas de investigación son: comunicación científica; creatividad publicitaria-nuevos formatos publicitarios y comunicación e infancia. Autora de varios libros y artículos en revistas indexadas. Pertenece a los comités científicos de diversas revistas españolas y portuguesas del área de comunicación. http://scholar.google.es/citations?user=dYPk_UoAAAAJ\&hl=es\&oi=ao

Jesús Segarra-Saavedra. DEA por la Universidad de Alicante. Investigador en Comunicación. Su principal línea de investigación analiza la "Publicidad Especial en Televisión" entendida como toda comunicación publicitaria televisiva distinta del spot convencional. Es editor técnico adjunto de Revista Mediterránea de Comunicación. 